\title{
sciendo
}

\section{THE FIRST INSIGHT INTO FULL-FAT SUPERWORM (ZOPHOBAS MORIO) MEAL IN GUPPY (POECILIA RETICULATA) DIETS: A STUDY ON MULTIPLE-CHOICE FEEDING PREFERENCES AND GROWTH PERFORMANCE*}

\author{
Joanna Kowalska ${ }^{1 \#}$, Mateusz Rawski ${ }^{1 \#}$, Natalia Homska ${ }^{1 \bullet}, Z_{\text {Zuzanna Mikołajczak }}^{2}$, \\ Bartosz Kierończyk ${ }^{2}$, Sylwester Świątkiewicz ${ }^{3}$, Roksana Wachowiak ${ }^{2}$, Katarzyna Hetmańczyk ${ }^{1}$, \\ Jan Mazurkiewicz ${ }^{1}$ \\ 'Department of Zoology, Laboratory of Inland Fisheries and Aquaculture, \\ Faculty of Veterinary Medicine and Animal Science, Poznań University of Life Sciences, \\ Wojska Polskiego 71 c, 60-625 Poznań, Poland \\ ${ }^{2}$ Department of Animal Nutrition, Faculty of Veterinary Medicine and Animal Science, \\ Poznań University of Life Sciences, Wołyńska 33, 60-637 Poznań, Poland \\ ${ }^{3}$ Department of Nutrition Physiology, National Research Institute of Animal Production, \\ 30-083 Balice n. Kraków, Poland \\ •Corresponding author: natalia.homska@up.poznan.pl \\ \#These authors equally contributed to paper authorship
}

\begin{abstract}
Insect meals are sustainable alternative protein sources in animal nutrition. However, the data on their application in petfood and ornamental fish nutrition are scarce. Thus the present study was undertaken to assess their usability in guppy (Poecilia reticulata) diets. The first experiment aimed to investigate the attractiveness of select insect meals for guppies, and the second evaluated superworm (Zophobas morio) meal monodiet effects. The first experiment (free-choice feeding test) lasted five days. Fish were given a choice between four attractants: fish meal, black soldier fly (Hermetia illuces) meal (HI), Madagascar cockroach (Gromphadorhina portentosa) meal (MC), and superworm (Zophobas morio) meal (ZM). The preliminary part of the study showed that the most frequently chosen attractant throughout the entire free-choice feeding test period was ZM. Based on the obtained results, the second part of the study was designed as a growth test with the use of a ZM monodiet compared to commercial feed. The experiment lasted 90 days, and 150 guppy fry were used. The fish were randomly divided into two groups (CON - commercial feed, ZM - Zophobas morio meal). No effects of dietary treatment were found in terms of survival rate, fish body length, or fish body length gain. The present study shows that $\mathrm{ZM}$ was the most preferred attractant and that a monodiet based on insect meal can be successfully applied in guppy fry nutrition.
\end{abstract}

Key words: guppy (Poecilia reticulata), insect meal, feed preferences, monodiet, free-choice feeding

\footnotetext{
*This study was supported by the Poznań University of Life Sciences by the statutory funding of the Laboratory of Inland Fisheries and Aquaculture.
} 
The worldwide pet market production increases annually by $4.5 \%$, which is faster than most areas of modern animal production. It is estimated that $85 \%$ of the income generated by the global pet market is based on pet food production and distribution (www.statista.com). In animal farming, the selection of feeds and feed components is based on economic calculations described by the cost of the feed per $\mathrm{kg}$ of weight gain and income generated by animal live weight sale. In contrast, in the case of pet growth performance, feed utilization and economic parameters are not calculated. The main actors in pet food selection are customers (pet owners) and their preferences, opinions, brand marketing and animal observations. The role of producers is to highlight key aspects that are also considered during pet food selection such as easy differentiation in the market and functional properties that can be obtained by innovative feed component use. This can be achieved with the use of alternative and environmentally sustainable feed materials, which contain beneficial bioactive health compounds. Considering all of the abovementioned aspects, the possibility of insect meal application as a novel material in pet food is highly justified. Moreover, insect biomass shows a higher level of environmental sustainability than most animal-derived feed materials that are applied in pet foods (Gahukar, 2016). Its production does not require high energy and water input (Dossey et al., 2016) and emits only trace amounts of greenhouse gases into the atmosphere (Oonincx et al., 2010), which are factors that are strongly required by an increasing share of consumers. One of the main ingredients in aquarium fish pet food is fish meal, but its production has a destructive effect on fish populations in the wild and generates a constantly increasing price caused by market deficits (Tacon and Metian, 2008; Gasco et al., 2018 a). The environmental sustainability of insect-derived feed materials is also increased by the fact that insect larvae have the ability to perform bioconversion and effectively use agricultural and food market byproducts in the production of their biomass (Oonincx et al., 2015; Kuttiyatveetil et al., 2019). Apart from that, they are characterized by high protein and lipid contents (Makkar et al., 2014) and the presence of beneficial health biocompounds, i.e., antimicrobial peptides and lauric acid (Gasco et al., 2018 b; Rawski et al., 2020). For these reasons, intensive research into insect usage for aquaculture feeds is ongoing (Lock et al., 2018; Mikołajczak et al., 2020; Weththasinghe et al., 2021; Rawski et al., 2021). Considering these facts, it is justified to research the use of insect meals in the nutrition of ornamental fish kept as pets to obtain results characterized by high scientific innovation and application. Moreover, the segment of premium pet food brands is increasingly growing in the market, and materials obtained from insects can find wide application prospects due to their environmental sustainability and marketing value. An important aspect is also the fact that insects are the natural food of many wild animals, including a wide range of fish species (Cardoso and Couceiro, 2017). The diet of some tropical fish species consists solely of aquatic and terrestrial insects (Vidotto-Magnoni and Carvalho, 2009). It should be emphasized that Poeciliidae are one of the most frequently kept ornamental fish in aquariums, and their most common representative is the guppy (Poecilia reticulata Peters, 1859), for which the consumption of insects in natural diets is common (Fernando et al., 2018; Lawal et al., 2012). Moreover, this species has been introduced beyond its natural range to reduce the infestation of mosquitoes and other 
insects (Seng et al., 2008). In addition, guppies have several characteristics that make them model organisms. These fish are used for research in many areas of science due to their high resistance to adverse environmental conditions (Auer, 2010), high fertility, short generation interval, small size, shoal type behaviour, and low level of aggression. These features result in both the reduction of costs and mortality minimization during experiments. Additionally, they are omnivorous fish characterized by a simultaneous tendency toward food selectivity depending on the characteristics and availability of the offered types of food (Seng et al., 2008; Fernando et al., 2018). Their preferences and feed selection strategy may be related to their sense of smell. Research shows that in a number of fish species, olfactory sensations play an important role in numerous life functions (Døving, 2007). However, the full mechanism of selection is unknown. What should be underlined of the most important parameters determining the usefulness of potential pet foods and their ingredients in ornamental fish nutrition is their palatability. High nutritional attractiveness and fish reaction also determine owners' feed reception. Moreover, these parameters translate into two positive aspects related to fish welfare, environmental conditions in aquariums and maintenance efforts. The first is the uneaten food amount; when it decreases, the probability of fluctuations in water parameters related to the excess decomposition of organic matter also decreases (Santamaría and Corredor-Santamaría, 2011). The second advantage of fast food intake is minimizing the loss of nutrients by dissolving them in water. The improvement of the environmental conditions for fish is correlated with the limitation of the loss of valuable chemical compounds from the provided foods and enables the improvement of production parameters without increasing production costs (Lemarie et al., 2004; Sun et al., 2012; Mohammadrezaei, 2020). Thus, the aim of the study was to assess the nutritional preferences of guppies in terms of insect meal selection and sensory attractiveness in the first experiment. On the basis of its result the second experiment aimed in empirical analysis of the effects of Zophobas morio (Fabricius, 1776) meal monodiet on guppy fry growth, development and survival rate.

\section{Material and methods}

\section{Ethics statement}

Studies on live animals were carried out in strict accordance with the recommendations of the National Ethics Commission (Warsaw, Poland). All members of the research staff were trained in animal care and handling. Fish health, welfare and the environmental conditions in the experimental tanks were checked twice daily by visual observation of animal behaviour according to Polish law and an EU directive (no 2010/63/EU).

\section{Experiment I - free-choice feeding test}

Technical conditions of the experiment

Four glass experimental tanks with dimensions of $0.3 \mathrm{~m} \times 0.3 \mathrm{~m} \times 0.35 \mathrm{~m}$ and a net capacity of $28 \mathrm{dm}^{3}$ were prepared. Each aquarium was filled with tap wa- 
ter and then equipped with identical cascade filters with a water flow efficiency of $200 \mathrm{l} / \mathrm{h}$ for mechanical and biological filtration and $25 \mathrm{~W}$ heaters with a thermostat set at $25^{\circ} \mathrm{C}$. The experimental tanks prepared in such a way were run for 20 days with working equipment to establish a nitrification cycle to avoid fluctuations in water parameters and ammonia poisoning after introducing the fish. The applied photoperiod was $12 \mathrm{~h}$ of light and $12 \mathrm{~h}$ of darkness.

\section{Preparation of experimental meals}

The attractants used were Madagascar cockroach (Gromphadorhina portentosa Schaum, 1853), black soldier fly (Hermetia illucens Linnaeus, 1758), superworm (Zophobas morio), and mealworm (Tenebrio molitor Linnaeus, 1758) meals as well as fish meal and pork gelatine as controls. The insects' larvae were provided by HiProMine S.A. They were air-dried at $40^{\circ} \mathrm{C}$ for $24 \mathrm{~h}$ to avoid the degradation of proteins and substances responsible for natural smell or taste properties. Then, dried larvae were ground into meal form. For acceptance tests, meals were solidified with pork gelatine water solution $\left(15 \mathrm{~g} / 100 \mathrm{ml}, 50^{\circ} \mathrm{C}\right)$. The proportion of meals and gelatine solution was $3: 2(\mathrm{~g}: \mathrm{g})$, and the mixture was poured on sterile petri dishes. When the mass solidified in the refrigerator $\left(4^{\circ} \mathrm{C}\right)$, discs with a diameter of $15 \mathrm{~mm}$ were cut from each component, and food in this form was administered to the fish. The control discs based on fishmeal and gelatine and gelatine only were analysed analogously. At this stage of preparation, the study of mealworms was discontinued because the mixture of mealworm meal and pork gelatine did not solidify properly.

\section{Animals and experimental methodology}

For the experiment, 60 adult guppies (30 males and 30 females) were used and randomly divided into four replicates, including 15 fish in each. The groups were placed in separate experimental tanks. The test consisted of two stages: a five-day acclimatization period followed by a five-day food preference trial. The first stage aimed to adapt the fish to environmental conditions. During this time, they were fed once a day with commercial fish food for ornamental fish, a dose that they were able to consume within 5 minutes. The second stage was the free-choice feeding test, the essence of which was equal access to the tested meals. Fresh discs were administered to the fish each day of the preference test, and they were placed at the bottom of the experimental tanks with equal space between them, each time in a random arrangement, and left there for 5 minutes. After this time, food was removed from the experimental tanks. On the first day of the food preference trial (day 0), no observations were made to avoid the influence of neophobic effects. In the days following the free-choice feeding test (days 1-4), observations of interest were carried out with the prepared foods. Feeding time was recorded with a digital camera (Panasonic, model DMC-FZ300) from the perspective of the top of the tank with 100 frames/second. The recordings were then analysed in terms of fish interest in particular foods in subsequent minutes of the feeding cycle and throughout the entire feeding cycle. The fish were defined as interested in the meal after taking some of the experimental discs at the point of measurement. To avoid animal starvation, they were fed $2 \mathrm{~h}$ after the experimental session until satiation. 


\section{Experiment II - fry rearing}

Technical conditions of the experiment

Before the start of the feeding tests, six glass experimental tanks with dimensions of $0.48 \mathrm{~m} \times 0.16 \mathrm{~m} \times 0.3 \mathrm{~m}$ and a net capacity of $23 \mathrm{dm}^{3}$ were prepared. They were placed in an isolated and draft-free place to minimize external stress factors and temperature fluctuations. Each aquarium was filled with tap water and then equipped with identical cascade filters with a water flow efficiency of $200 \mathrm{l} / \mathrm{h}$ acting in mechanical and biological filtration. Heaters were not necessary due to the constant water temperature in the experimental room at $24 \pm 0.5^{\circ} \mathrm{C}$. The experimental tanks were run for 20 days with working equipment to establish a nitrification cycle to avoid fluctuations in water parameters and ammonia poisoning after introducing the fish. To prevent animals from jumping out, each tank was protected with a glass lid. The applied photoperiod was $12 \mathrm{~h}$ of light and $12 \mathrm{~h}$ of darkness.

\section{Experimental food preparation}

The same batch of superworm (Zophobas morio) larval meal as that used in the free-choice feeding test was applied. The insects were ground, and experimental food in this form was placed into a plastic screw-cap vial. Commercial fish feed was used as a control. To maintain identical forms, the commercial feed was ground and stored in screw-cap plastic vials. Both feeds were stored at $4^{\circ} \mathrm{C}$ throughout the experimental period, and their odour and visual appearance were checked daily before each feeding to avoid spoiling. During the entire duration of the test, no visual or odour changes were noted. The nutritional values of the superworm meal and commercial feed used are given in Table 1. For commercial diet it is based on producers declaration, for Zophobas morio meal due to lack of product standardization it was analysed in certified reference laboratory J.S. Hamilton Sp. z o.o. according to AOAC methods.

Table 1. Chemical composition and energy content of experimental foods

\begin{tabular}{lcc}
\hline & Commercial feed & Zophobas morio meal \\
\hline Crude protein (\%) & 45.0 & 49.3 \\
Crude fat (\%) & 15.0 & 33.6 \\
Ash (\%) & 6.90 & 2.92 \\
Crude fibre (\%) & 3.30 & 5.68 \\
Nitrogen-free extract (\%) & 23.80 & 5.40 \\
P (\%) & 0.90 & 0.60 \\
Gross energy (MJ/kg) & 21.2 & 26.8 \\
\hline
\end{tabular}

\section{Animals and experimental methodology}

The monodiet feeding experiment lasted for 90 days; 150 individuals of guppy (Poecilia reticulata) fry with an average body length of $8.5( \pm 2) \mathrm{mm}$ were used. The fish were randomly divided into two groups (CON - commercial feed, ZM Zophobas morio meal). Each group consisted of three replicates of 25 individuals in each experimental tank - replication. Individual experimental tanks were assigned 
to groups alternately. This experimental design ensured an even distribution of environmental factors. Fish were fed once a day until visual satiation. In addition to feeding, the technical condition of equipment and physical condition of the animals were checked two times each day, and if necessary, dead individuals were removed and noted. Cleaning was carried out once a week, during which $20 \%$ of the water in each of the tanks was removed and replenished with tap water of the same temperature. At the same time, organic residues from the bottom and algae deposited on the tank walls were cleaned off. Then, the filter media were flushed in water siphoned from the tanks for mechanical particle removal. Fish measurements were carried out on days 1, 30, 60, and 90 of the experiment. Each experimental tank was analysed in terms of the survival ratio (\%), individual fish body length $(\mathrm{mm})$, and individual fish body length gain $(\mathrm{mm})$. The petri dish was poured with water from the experimental tank, and then all fish were caught and placed in the prepared dishes, which were placed on graph paper. A series of photographs was taken, and then fish were returned to the experimental tank. Measurements were taken using ImageJ software (National Institutes of Health).

\section{Statistical analysis}

The statistical analysis was performed with the use of SAS 9.3 software with a significance level of $\mathrm{P} \leq 0.05$. One-way analysis of variance and Duncan's multiple range test were used to analyse the number of foraging fish in each minute of the test and to compare the interest in individual attractants over days, minutes, and the entire experimental period. Student's T-test was used to analyse body length, body length gain, and survival rate.

\section{Results}

\section{Experiment I - free-choice feeding test}

The results of the experiment are presented in Figures 1, 2, 3, 4, and 5, the values shown therein represent average values. The overall interest of the fish in the given foods ranged from 50.0 to $60.0 \%$ of fish present in tank during observation points. There were no significant differences among the days of the test but a slight numerical increase of foraging fish share was observed each day. The number of foraging fish did not differ among the observation points during each feeding session (from 1 st to 5 th minute) and varied from 49.2 to $57.5 \%$. The overall interest of fish was the highest in the case of Zophobas morio meal (51.4\%). In the case of Hermetia illucens and Gromphadorhina portentosa meal attractiveness was significantly lower (20.8 and 17.0\% respectively). The lowest fish interest was characteristic of fish meal $(12.0 \%)$ which was significantly lower than in the case of Zophobas morio, Hermetia illucens meals, however, it did not differ from Gromphadorhina portentosa meal. In the case of daily measurements fish meal attracted from 7.9 to $14.2 \%$ of fish, Hermetia illucens meal from 16.9 to $25.6 \%$ and Gromphadorhina portentosa meal from 7.2 to 22.2 and Zophobas morio from 48.6 to $59.0 \%$. Zophobas morio 
meal acceptance was significantly higher than all other attractants, and numerically was increasing with each day of the experiment. Considering foraging fish share during the observation points during feeding sessions, the pattern of Zophobas morio the highest attractiveness and its increase was even more visible - it gained from $36.0 \%$ in the first minute to over $60 \%$ in fourth and fifth. While for fish meal it numerically decreased from 16.0 to $8.2 \%$, Hermetia illucens meal from 26.1 to $18.7 \%$, and Gromphadorhina portentosa meal from 18.8 to $15.2 \%$.

Superworm (Zophobas morio) meal was the most frequently chosen attractant, and this frequency increased over the following days and minutes of the free choice feeding test (Figures 3-5).

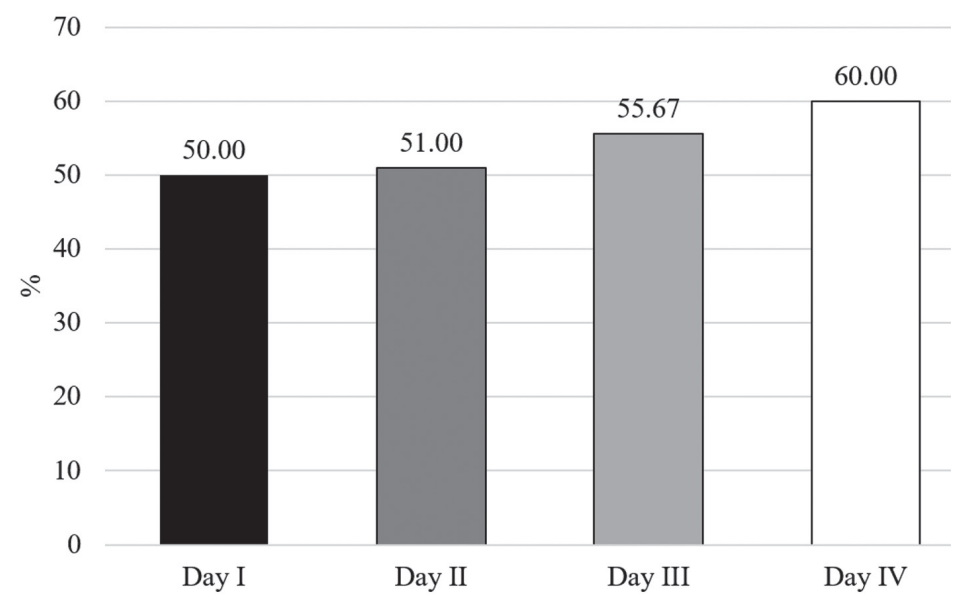

Lack of letter descriptions $(a, b, c)$ indicates differences between treatments $(\mathrm{P}=0.0958)$.

Figure 1. The average percentage of foraging individuals at the measurement time points during each day of the free-choice feeding test

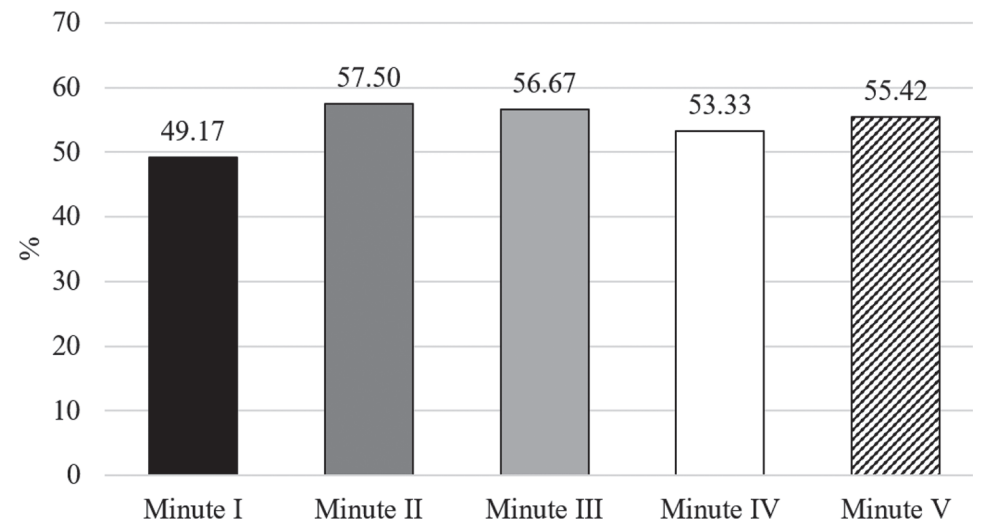

Lack of letter descriptions $(a, b, c)$ indicates differences between treatments $(\mathrm{P}=0.5168)$.

Figure 2. The average percentage of foraging individuals at the measurement time points during each minute of the free-choice feeding test 


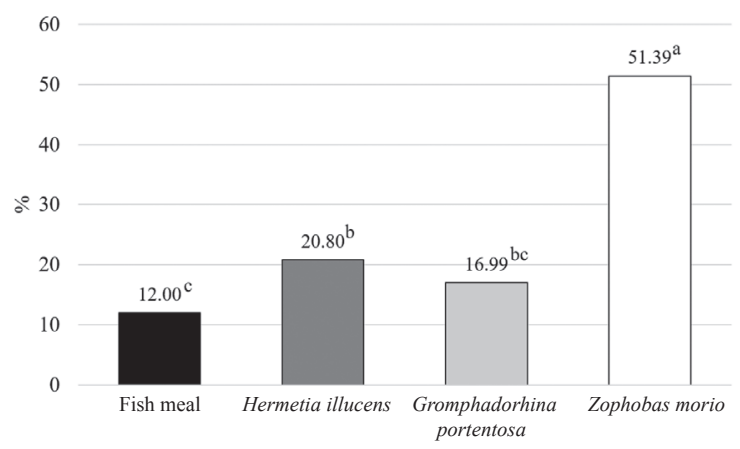

Different letters $(\mathrm{a}, \mathrm{b}, \mathrm{c})$ indicate differences between treatments $(\mathrm{P}<0.0001)$.

Figure 3. The average percentage of total interest in tested attractants throughout the entire period of the free-choice feeding test

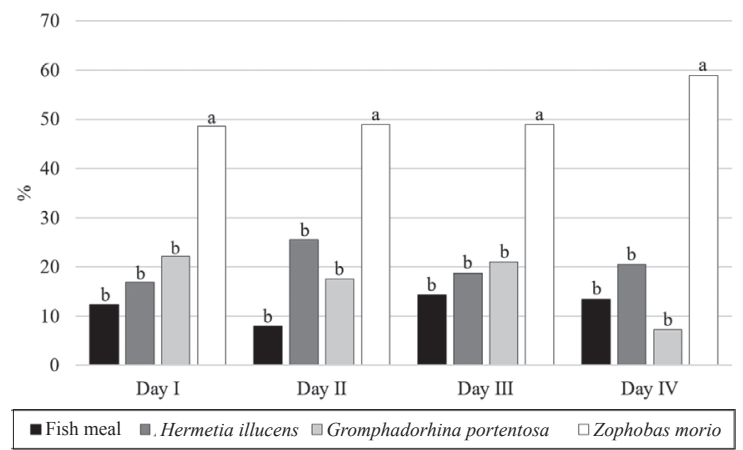

Different letters ( $\mathrm{a}, \mathrm{b}$ ) indicate differences between treatments (I day $\mathrm{P}=0.000128$, II day $\mathrm{P}=0.00414$, III day 0.0000114, IV day $\mathrm{P}=0.0000577$ ).

Figure 4. The average percentage interest of fish in given attractants over individual days of the freechoice feeding test

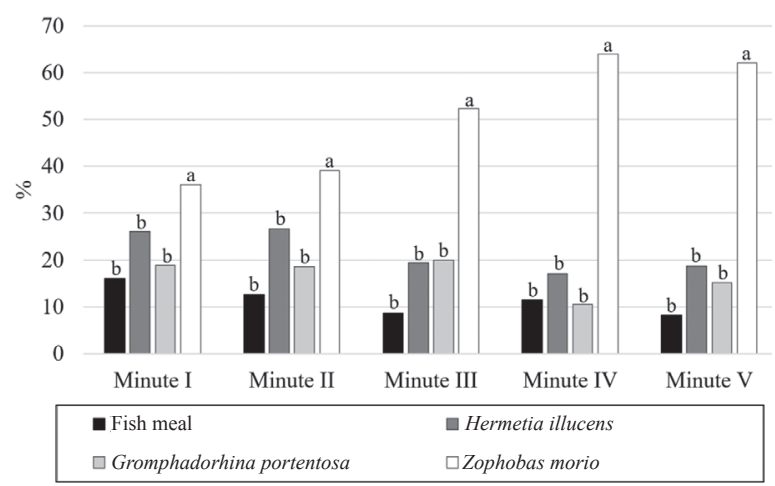

Different letters $(a, b)$ indicate differences between treatments (I minute $\mathrm{P}=0.00629$, II minute $\mathrm{P}=0.00212$, III minute $\mathrm{P}=0.00282$, IV minute $\mathrm{P}=0.0000000376$, V minute $\mathrm{P}=0.00000709$ ).

Figure 5. The average interest of fish in given attractants during individual minutes of the free-choice feeding test 


\section{Experiment II - monodiet}

The results of the experiment are presented in Table 2. Summarizing the entire experimental period, no statistically significant differences were found in terms of survival ratio, individual fish body length, or individual fish body length gain. However, fish fed a monodiet showed numerically lower mean body length, mean body length gain and survival rate. Significant differences were observed in mean body length at day 30 and mean body length gain for the period of 1 to 30 days; in both cases, lower values were observed in Zophobas morio monodiet-fed fish.

Table 2. Growth parameters of guppies fed a commercial diet and Zophobas morio in specific periods of the monodiet experiment

\begin{tabular}{l|cccc}
\hline \multicolumn{1}{c|}{ Days of test } & Commercial feed & Zophobas morio & P-value \\
\hline \multicolumn{4}{c}{ Mean body length $(\mathbf{m m})$} \\
1 & $8.5( \pm 0.2)$ & $8.5( \pm 0.2)$ & 0.9300 \\
30 & $12.6 \mathrm{a}( \pm 0.2)$ & $12.0 \mathrm{~b}( \pm 0.1)$ & 0.0260 \\
60 & $13.5( \pm 0.1)$ & $13.4( \pm 0.9)$ & 0.8125 \\
90 & $15.0( \pm 0.3)$ & $14.5( \pm 0.8)$ & 0.3548 \\
& Mean body length gain $(\mathbf{m m})$ & \\
$1-30$ & $4.1 \mathrm{a}( \pm 0.2)$ & $3.5 \mathrm{~b}( \pm 0.1)$ & 0.0260 \\
$30-60$ & $1.0( \pm 0.2)$ & $1.4( \pm 1.0)$ & 0.5151 \\
$60-90$ & $1.5( \pm 0.4)$ & $1.1( \pm 0.6)$ & 0.3625 \\
$1-90$ & $6.5( \pm 0.3)$ & $6.0( \pm 0.8)$ & 0.3548 \\
& Survival rate $(\mathbf{\%})$ & 0.3868 \\
$1-30$ & $93.3( \pm 2.3)$ & $96.0( \pm 4.0)$ & 0.1523 \\
$30-60$ & $97.2( \pm 2.5)$ & $88.7( \pm 6.8)$ & 0.5095 \\
$60-90$ & $88.3( \pm 4.9)$ & $83.9( \pm 9.0)$ & 0.4409 \\
$1-90$ & $80.0( \pm 4.0)$ & $72.0( \pm 14.4)$ & \\
\hline
\end{tabular}

$\mathrm{a}, \mathrm{b}$ - values in rows with different letters differ significantly $(\mathrm{P} \leq 0.05) . \mathrm{n}=3$ per treatment, representing all fish in each tank.

\section{Discussion}

Companion animals and pets keeping is long-term human activity which has changed its character over the centuries from considering their presence in human households as useful to the current recreational form. Despite the fact that some fish species, i.e. koi carps, have been kept for centuries the large-scale rearing and breeding of aquatic animals as pets is a relatively new industry. Therefore, the nutrition of ornamental fish is mainly based on comparing research results regarding the feeding consumption of fishes (Sales and Janssens, 2003). Only a few tests have been carried out on the food preferences of ornamental fish in terms of insect meals. However, based on other, better-studied materials, it is known that protein and fat content in food play a significant role in the growth and sexual development of guppies (Suting 
et al., 2013). It is also widely reported that insect larvae are characterized by a high content of both of these nutrients (Sun et al., 2012; Barroso et al., 2014). Moreover, insect meals contain a number of beneficial health substances, including antimicrobial peptides that support resistance to pathogens, chitin with prebiotic effects and lauric acid known for antibacterial, antiviral and anti-inflammatory actions (Yi et al., 2014; Gasco et al., 2018; Henry et al., 2018). For these reasons, insects seem to be a promising source of essential amino acids and energy- and health-promoting substances for the pet food industry. However, it should be emphasized that their nutritional value depends on many factors including growth stage and nutrition rearing conditions (Gasco et al., 2018 b). Nutritional value is mostly influenced by the species, stage of development, diet on which insects are kept, and method of their processing (Halloran et al., 2016; Zielińska et al., 2018). Due to the high potential of feed components derived from insects, there is high variability in nutritional value (Nogales-Mérida et al., 2019). In the last decade, an increasing number of nutritional tests have been carried out to determine the possibility of using insects as an alternative source of nutrients for farmed fish. Studies carried out until now have shown that many fish species efficiently utilize feed containing insects (Belghit et al., 2018; Fontes et al., 2019; Xu et al., 2020). Moreover, research conducted on some species, including the African catfish (Clarias gariepinus), has shown that it eats feed with the addition of insect meals more willingly ( $\mathrm{Ng}$ et al., 2001). This trend has also been observed in the Siberian sturgeon (Acipenser baerii) and is probably related to the presence of specific aromatic compounds in insects and their free amino acid composition as well as the lower molecular weight of insect proteins (Rawski et al., 2020). Nonetheless, as mentioned previously, there is little research that directly relates to the food preferences of ornamental fish. The results obtained in this study prove that guppies also have a significant interest in insect food. It seems particularly important that individual insect species were selected with different frequencies. This is probably related to their specific sensory properties and variability in nutritional composition (Nogales-Mérida et al., 2019). The extent of development of taste and sense organs varies depending on the fish species. Guppies react behaviourally to olfactory signals from both potential breeding partners and potential predators (Shohet and Watt, 2004), and as a microsomatic fish, they are characterized by a relatively simple olfactory organ (Lazzari et al., 2007). The degree of their development can be compared to that of the larval stages of macrosomatic fish. This also means that the behaviour and nutritional preferences of a wide spectrum of other ornamental fish with similar characteristics can be significantly influenced by their sense of smell. Each of them distinguishes the taste and aroma properties of the consumed food, which makes it possible for them to select food suitable and preferable to eat (Døving, 2007). The senses enabling the assessment of the palatability of eaten food may affect faster development, improve fish body and health condition, and thus increase the probability of survival. It was therefore assumed that guppies with access to foods characterized by different nutritional values would choose the food with the most favourable nutrient content (Yacoob and Browman, 2007; Zandona et al., 2011). A mechanism to find the most beneficial food with the lowest possible energy expenditure is commonly found in many species (Metcalfe and Thomson, 1995; Aw 
et al., 2009). This hypothesis was also supported by the results of studies determining the impact of a diet with insect inclusion on the growth and physiology of another popularly kept ornamental fish, the common platy (Xiphophorus maculatus). It has been proven that replacing fish meal with black soldier fly (Hermetia illucens) meal in their diet may have a positive effect on the condition of the gastrointestinal tract and fish reproduction (Mugnai et al., 2019). The possibility of using silkworms (Bombyx mori) in the nutrition of several species of ornamental fish, such as silver barb (Barbonymus gonionotus), snakeskin gourami (Trichogaster pectoralis), and red zebra (Maylandia estherae), was previously shown by Karthick Raja et al. (2019) who proved that introducing these insects into the diet has a positive effect on many fish growth parameters and health indicators. However, the condition for maintaining these positive effects does not exceed a certain percentage threshold of silkworm inclusion in food, which varies depending on fish species and phase of development. Studies carried out on zebrafish (Danio rerio), aimed at determining the influence of insects in the diet on several physiological features showed that, apart from being an excellent source of nutrients, the presence of insects in food can improve the health and longevity of the fish (Zarantoniello et al., 2020). It was previously shown that guppies are able to utilize a monodiet consisting of insects (Adil et al., 2014). Our research provides data on the successful rearing of guppy fry using a superworm (Zophobas morio) monodiet. Superworm meal can be a suitable source of nutrients for guppies. Lower growth performance results may be justified by the non-balanced character of nutritive value in the case of a monodiet in comparison with a complete commercial diet. However, it should be emphasized that guppies are characterized by very high nutritional flexibility (Ganassin et al., 2020). Despite the promising results, it is necessary to carry out further research to determine the critical thresholds of the use of insects in ornamental fish nutrition, after which the positive effects will begin to fade. The results of the present study suggest that Zophobas morio meal may be a valuable element of a complete menu of diets for guppies. Moreover, the use of meals may be more efficient than offering whole larvae due to the fish and food size ratio. It has been proven that guppies grow faster when fed finely ground powder than when fed flakes (Harpaz et al., 2005) and that guppies prefer food in a more accessible form (Fernando et al., 2018). Differences were also noted in the case of black soldier flies fed to ornamental fish as whole larvae or meal (Sinansari and Fahmi, 2020). Therefore, potentially attractive food given in an inappropriate form may be ignored by the fish. In conclusion, there is still too little data available to clearly define the effects of long-term feeding of foods containing insects on fish. It also seems justified to conduct further studies aimed at determining the food preferences of commonly kept ornamental fish and to analyse the effects and possibility of using insects in their nutrition.

\section{Conclusions}

Guppy (Poecilia reticulata) prefers insect meal consumption over fish meal, which is commonly used as a protein source in commercial ornamental fish foods. Therefore, insects can increase the attractiveness and palatability of food. There is a lack of data on the nutrition of commonly kept ornamental fish, and due to the ex- 
pected development of the pet market, there will be increased demand for pet foods designed for ornamental fish. Therefore, it is justified to test the food preferences of such fish and to research the influence of potential food components on their growth and health.

\section{References}

A d i 1 S., Ş i ş m a n T., İ c e k a r a Ü. (2014). An investigation on the growth and reproductive performance of Poecilia reticulata (Peters) (Cyprinodontiformes: Cyprinidae) fed diets with dried insects. Mun. Ent. Zool., 9: 638-644.

A u e r S.K. (2010). Phenotypic plasticity in adult life-history strategies compensates for a poor start in life in Trinidadian guppies (Poecilia reticulata). Am. Nat., 176: 818-829.

Aw J.M., Holbrook R.I., de Perera T.B., Kacelnik A. (2009). State-dependent valuation learning in fish: Banded tetras prefer stimuli associated with greater past deprivation. Behav. Process., 81: 333-336.

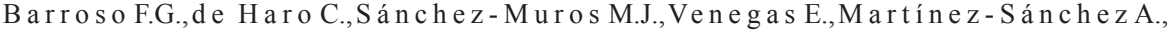
Pére z-B a ñón C. (2014). The potential of various insect species for use as food for fish. Aquaculture, 422: 193-201.

Belghit I., Liland N.S., Waagbø R., Biancarosa I., Pelusio N., Li Y., Lock E.J. (2018). Potential of insect-based diets for Atlantic salmon (Salmo salar). Aquaculture, 491: 72-81.

Card o s o A.C., Cou c e iro S.R.M. (2017). Insects in the diet of fish from Amazonian streams, in western Pará, Brazil. Mar. Freshw. Res., 68: 2052-2060.

Dos se y A.T., Morale s-R a mo s J.A., Roj a s M.G. (2016). Editors. Insects as sustainable food ingredients: production, processing and food applications. Academic Press.

D øv in g K.B. (2007). The functional organization of the fish olfactory system. Prog. Neurobiol., 82: $80-86$.

Fernando G.A.W., Jayakody S., Wijenayake W.H.K., Galappaththy G.N., Yataw a r a M., H a r i s h c h and r a J. (2018). A comparison of the larvivorous habits of exotic Poecilia reticulata and native Aplocheilus parvus. BMC Ecol., 18: 1-12.

Fontes T.V., de Oliveira K.R.B., Gomes Almeida I.L., Maria Orlando T., Rodrigues P.B., Cost a D.V.D. (2019). Digestibility of insect meals for Nile tilapia fingerlings. Animals, 9: 181

G a h u k a r R.T. (2016). Edible insects farming: efficiency and impact on family livelihood, food security, and environment compared with livestock and crops. In: Insects as sustainable food ingredients. Academic Press, pp. 85-111.

G a na s s in M.J., F rot a A., M un iz C.M., B a u m g a r tn er M.T., H a h n N.S. (2020). Urbanisation affects the diet and feeding selectivity of the invasive guppy Poecilia reticulata. Ecol. Freshw. Fish, 29: 252-265.

Gasco L., Gai F., Maricchiolo G., Genovese L., Ragonese S., Bottari T., Carus o G. (2018 a). Fishmeal alternative protein sources for aquaculture feeds. In: Feeds for the aquaculture sector. Springer, Cham, pp. 1-28.

G a s co L., F in ke M., Van Hu is A. (2018 b). Can diets containing insects promote animal health? J. Insects Food Feed., 4: 1-4.

Halloran A., Roos N., Eilenberg J., Cerutti A., Bruun S. (2016). Life cycle assessment of edible insects for food protein: a review. Agron. Sustain. Dev., 36: 57.

H a r p a z S., S l o s m a n T., S e g e v R. (2005). Effect of feeding guppy fish fry (Poecilia reticulata) diets in the form of powder versus flakes. Aquac. Res., 36: 996-1000.

Hen ry M.A., Gas co L., Chat zi fot is S., P i c colo G. (2018). Does dietary insect meal affect the fish immune system? The case of mealworm, Tenebrio molitor on European sea bass, Dicentrarchus labrax. Dev. Comp. Immunol., 81: 204-209.

Karthick Raja P., Aanand S., Stephen S ampathkumar J., Padmavathy P. (2019). Silkworm pupae meal as alternative source of protein in fish feed. J. Entomol. Zool., 7: 78-85.

K i 1 a r s k i W. (2012). Fish anatomy (in Polish). Warsaw, Poland, PWRiL, 1st ed., 189 pp. 
Kuttiy a tve et il J.R., Mitra P., Goldin D., N i ckers on M.T., Tan a ka T. (2019). Recovery of residual nutrients from agri-food byproducts using a combination of solid-state fermentation and insect rearing. Int. J. Food Sci. Technol., 54: 1130-1140.

Law 1 M.O., Edokpayi C.A., Osibona A.O. (2012). Food and feeding habits of the guppy, Poecilia reticulata, from drainage canal systems in Lagos, Southwestern Nigeria. West Afr. J. Appl. Ecol., 20: 1-9.

Lazzari M., B ettin i S., Cian i F., Frances ch in i V. (2007). Light and transmission electron microscopy study of the peripheral olfactory organ of the guppy, Poecilia reticulata (Teleostei, Poecilidae). Microsc. Res. Tech., 70: 782-789.

Lemarie G., Dos dat A., Covè s D., Dutto G., Gas s e t E., P ers on - L e Ruyet J. (2004). Effect of chronic ammonia exposure on growth of European seabass (Dicentrarchus labrax) juveniles. Aquaculture, 229: 479-491.

L o c k E.J., B i a n c a r o s a I., G a s c o L. (2018). Insects as raw materials in compound feed for aquaculture. In: Edible insects in sustainable food systems. Springer, Cham., pp. 263-276.

M a k k ar H.P., Tran G., H e u zé V., A n k e r s P. (2014). State-of-the-art on use of insects as animal feed. Anim. Feed Sci. Technol., 197: 1-33.

Met c a lfe N.B., Th o m s o n B.C. (1995). Fish recognize and prefer to shoal with poor competitors. Proc. Royal Society of London. Series B: Biol. Sci., 259: 207-210.

Mikołajczak Z., Rawski M., Mazurkiewicz J., Kierończyk B., Józefiak D. (2020). The effect of hydrolyzed insect meals in sea trout fingerling (Salmo trutta $\mathrm{m}$. trutta) diets on growth performance, microbiota and biochemical blood parameters. Animals, 10: 1031.

Mohammadrezaei D. (2020). The effect of media type on ammonia levels and growth performance of guppy (Poecilia reticulata) in recirculating systems. ISFJ, 28: 25-33.

Mugnai C., Salio C., Munari C., A imar P., Falzone M., Pastorino P., Sicuro B. (2019). Preliminary results of fishmeal substitution with insect meal (Hermetia illucens) on Platy (Xiphophorus maculatus) feeding: effect on gut health, reproductive parameters and water quality. Proc. 23rd Congress of the European Society of Veterinary and Comparative Nutrition. European Society of Veterinary and Comparative Nutrition, pp. 56.

Ng W.K., L i e w F.L., A ng L.P., Wo n g K.W. (2001). Potential of mealworm (Tenebrio molitor) as an alternative protein source in practical diets for African catfish, Clarias gariepinus. Aquac. Res., 32: $273-280$.

Nogales-Mérida S., Gobbi P., Józefiak D., Mazurkiewicz J., Dudek K., Rawski M., Kierończyk B., Józefiak A. (2019). Insect meals in fish nutrition. Rev. Aquac., 11: 1080-1103.

O on incx D.G.,Van It t e rb e e ck J.,He et ka mp M.J.,Van D en Brand H.,Van Loon J.J., Van Huis A. (2010). An exploration on greenhouse gas and ammonia production by insect species suitable for animal or human consumption. PloS one, 5 (12).

Oonincx D.G., Van Broekhoven S., Van Huis A., van Loon J.J. (2015). Feed conversion, survival and development, and composition of four insect species on diets composed of food by-products. PloS one, 10 (12).

Rawski M., Mazurkiewicz J., Ki erończyk B., Józefiak D. (2020). Black soldier fly full-fat larvae meal as an alternative to fish meal and fish oil in Siberian sturgeon nutrition: the effects on physical properties of the feed, animal growth performance, and feed acceptance and utilization. Animals, 10: 2119.

Rawski M., Mazurkiewicz J., Ki erończyk B., Józefiak D. (2021). Black soldier fly full-fat larvae meal is more profitable than fish meal and fish oil in Siberian sturgeon farming: the effects on aquaculture sustainability, economy and fish GIT development. Animals, 11: 604.

S a les J., Jans sens G.P. (2003). Nutrient requirements of ornamental fish. Aquat. Living Resour., 16: 533-540.

S a n t a m a ría Y.V., C or re d or - S a n t a ma ría W. (2011). Nutritional requirements of freshwater ornamental fish: a review. Rev. MVZ Córdoba, 16: 2458-2469.

S e n g C.M., S e tha T., N e a 1 o n J., S o c h e a t D., C h a n th a N., N a th a n M.B. (2008). Community-based use of the larvivorous fish Poecilia reticulata to control the dengue vector Aedes aegypti in domestic water storage containers in rural Cambodia. J. Vector. Ecol., 33: 139-144.

S h o h e t A.J., Wat t P.J. (2004). Female association preferences based on olfactory cues in the guppy, Poecilia reticulata. Behav. Ecol. Sociobiol., 55: 363-369. 
Sinansari S., F ahmi M.R. (2020). Black soldier fly larvae as nutrient-rich diets for ornamental fish. In: IOP Conference Series: Earth and Environmental Science. IOP Publishing, 493: 012027.

S u n H., L ü K., M inter E.J., Chen Y., Yang Z., Montagnes D.J. (2012). Combined effects of ammonia and microcystin on survival, growth, antioxidant responses, and lipid peroxidation of bighead carp Hypophthalmythys nobilis larvae. J. Hazard. Mater., 221: 213-219.

S u t in g P.S., M a n d a 1 S.C., P a te 1 A.B. (2013). Effect of different dietary lipid sources on growth and reproductive performance of guppy (Poecilia reticulata). Isr. J. Aquac., 65: 1-6.

T a c o n A.G., M e ti a n M. (2008). Global overview on the use of fish meal and fish oil in industrially compounded aquafeeds: Trends and future prospects. Aquaculture, 285: 146-158.

Vidotto-Magnoni A.P., Carvalho E.D. (2009). Aquatic insects as the main food resource of fish the community in a Neotropical reservoir. Neotrop. Ichthyol., 7: 701-708.

We ththas inghe P., Hansen J.Ø., Nøkland D., Lagos L., Rawski M., Øverland M. (2021). Full-fat black soldier fly larvae (Hermetia illucens) meal and paste in extruded diets for Atlantic salmon (Salmo salar): Effect on physical pellet quality, nutrient digestibility, nutrient utilization and growth performances. Aquaculture, 530: 735785.

X u X., J i H., B e $\mathrm{g}$ h i t I., S u n J. (2020). Black soldier fly larvae as a better lipid source than yellow mealworm or silkworm oils for juvenile mirror carp (Cyprinus carpio var. specularis). Aquaculture, 527: 735453

Yacoob S.Y., Browman H.I. (2007). Olfactory and gustatory sensitivity to some feed-related chemicals in the Atlantic halibut (Hippoglossus hippoglossus). Aquaculture, 263: 303-309.

Yi H.Y., Chow dhury M., Huang Y.D., Yu X.Q. (2014). Insect antimicrobial peptides and their applications. Appl. Microbiol. Biotechnol., 98: 5807-5822.

Zandona E., A u er S.K., Kilham S.S., How ard J.L., López-Sepulcre A., O'Conn or M.P., Reznick D.N. (2011). Diet quality and prey selectivity correlate with life histories and predation regime in Trinidadian guppies. Funct. Ecol, 25: 964-973.

Zarantoniello M., Randazzo B., Gioacchini G., Truzzi C., Giorgini E., Riolo P., L u c o n - X i c c a to T. (2020). Zebrafish (Danio rerio) physiological and behavioural responses to insect-based diets: A multidisciplinary approach., Sci. Rep., 10: 1-16.

Zielińska E., Karaś M., B araniak B. (2018). Comparison of functional properties of edible insects and protein preparations thereof. Lwt, 91: 168-174.

Received: 12 V 2021

Accepted: 26 VIII 2021 